\title{
Sociedade limitada unipessoal - SLU: O melhor para uma startup?
}

\author{
Society limited one-person - SLU: The beast for a startup? \\ Sociedad Limitada unipersonal - SLU: ¿Lo mejor para una startup?
}

\section{Resumo}

Este artigo tem por finalidade abordar perspectivas relacionadas ao empreendedorismo e inovação e quais os tipos de empresas e suas diferenciações, bem como as dificuldades encontradas pelas mesmas para existiram e tratar mais afundo as dificuldades de uma STARTUP, ponto este que culminará na demonstração das vantagens da Sociedade Limitada Unipessoal, e porque esta se mostra a mais adequada na escolha do regime societário dessa empresa que tem por ideia ser inovadora. Norteando o objetivo deste trabalho, o presente estudo utilizou-se de literaturas, doutrinas e de leis que tratam da temática levantada, onde autores evidenciam definições e procedimentos que devem ser adotados no tipo societário, aclarando assim o entendimento que se tem nessa esfera empresarial. Com fundamento no estudo desenvolvido, observou-se que a Sociedade Limitada Unipessoal - SLU por dispor de especificidades e regramento diferenciado, torna-se menos burocrática e, por conseguinte, menos oneroso, oportunizando consequentemente uma melhor evolução e crescimento do empreendedor no mercado de trabalho.

Palavras-chave: Empreendedorismo; Startup; SLU; Inovação.

\begin{abstract}
This article is to address perspectives related to entrepreneurship and innovation and what are the types of companies and their differentiations, as well as the difficulties encountered by them to exist and to deal more deeply with the difficulties of a STARTUP, a point that will culminate in the demonstration of the advantages of the Single-Member Limited Liability Company, and why this is the most appropriate choice in the corporate regime of this company that has the idea of being innovative. Guiding the objective of this work, the present study used literatures, doctrines and laws that deal with the theme raised, where authors show definitions and procedures that must be adopted in the corporate type, thus clarifying the understanding that one has in this business sphere. Based on the study developed, it was observed that the Single-Member Limited Liability Company - SLU, by having specificities and differentiated rules, becomes less bureaucratic and therefore less costly, consequently providing an opportunity for better evolution and growth of the entrepreneur in the labor market.
\end{abstract}

Keywords: Entrepreneurship; Startup; SLU; Inovation.

\section{Resumen}

Este artículo es abordar las perspectivas relacionadas con el emprendimiento y la innovación y cuáles son los tipos de empresas y sus diferenciaciones, así como las dificultades con las que se encuentran para existir y abordar más profundamente las dificultades de una STARTUP, punto que culminará con la demostración de las ventajas de la Sociedad Unipersonal de Responsabilidad Limitada, y por qué ésta es la más adecuada en la elección del régimen 
societario de esta empresa cuya idea es ser innovadora. Orientando el objetivo de este trabajo, este estudio utilizó literaturas, doctrinas y leyes que tratan del tema planteado, donde los autores muestran definiciones y procedimientos que deben ser adoptados en el tipo societario, aclarando así el entendimiento que se tiene en esta esfera empresarial. Con base en el estudio desarrollado, se observó que la Sociedad de Responsabilidad Limitada Unipersonal - SLU, dadas sus especificidades y regulaciones diferenciadas, se torna menos burocrática $\mathrm{y}$, consecuentemente, menos costosa, brindando así oportunidades para una mejor evolución y crecimiento del empresario en el mercado de trabajo. Palabras clave: Emprendimiento; Startup; SLU; Inovacion.

\section{Introdução}

A inovação jurídica criada pela MP 881/2019, foi alterada para lei 13.874/2019; esta, por sua vez, trata do que é a Sociedade Limitada Unipessoal (SLU) e tem como objetivo principal desburocratizar a criação de uma empresa no Brasil, instituto ainda pouco abordado na doutrina empresarial. Assim, deste artigo tem o interesse em relacionar o tipo societário e a crescente demanda brasileira por startups, as quais, são modelos de negócios criados com um capital reduzido e com margem de lucros alta e rápida, em um modelo repetível e escalável, principalmente em um universo integralizado pelas novas mídias como a internet através das redes sociais.

Com objetivo de facilitar compreensão sobre o tema, pretende-se abordar as definições sobre empreendedorismo, Startup e SLU, com vistas de apresentar reflexões que sugerem ser, esta legislação, uma condição de inovação sobre o tema, principalmente em relação a lei 13.874/2019 que é a chamada Lei de Liberdade Econômica (LLE) e a Lei Complementar (LC) $\mathrm{n}^{\circ}$ 167/2019 que institui a Empresa Simples de Crédito e cria o Inova Simples, definindo o que é Startup para a lei brasileira e delimitando seu regime para as empresas que sejam autodeclaradas startups, para o estímulo de sua criação e desenvolvimento como catalisadoras da obtenção de renda e surgimento de empregos no Brasil.

Com isso, a motivação em tratar desse tema, surgiu, por considerar importante o aprimoramento das atitudes empreendedoras, buscando informar a população sobre um novo tipo societário e a facilidade em criá-lo, já que há pouco tempo atrás a criação de uma empresa no Brasil era muito burocrática onde se demandava muito tempo, como o registro em junta comercial, obtenção de alvará na prefeitura, formalização de crédito em banco, procedimentos estes que as leis acima citadas suprimiram, facilitando a criação de empresas, principalmente aos empreendedores individuais.

\section{Metodologia}

Na construção deste artigo utilizou-se como investigação o estudo descritivo bibliográfico. Nesse sentido, num primeiro momento foi realizado o levantamento de literatura dispondo sobre a temática abordada. Desta maneira, investigou-se artigos, livros e leis, trazendo assim escopo de pesquisa exploratória descritiva para o presente texto.

Em relação à pesquisa bibliográfica, Gil (2008) salienta que esta pesquisa é construída com base em material já elaborado, tendo em sua constituição artigos científicos e livros como arcabouço principal. De acordo com Gil (2008), pesquisam podem ser desenvolvidas exclusivamente com a natureza bibliográfica, sendo que a grande maioria dos estudos exploratórios são definidos como pesquisas bibliográficas.

Lakatos e Marconi (2007) elucida que a pesquisa bibliográfica pode ser percebida como base para toda e qualquer pesquisa de cunho científico. De outra maneira, o tipo de pesquisa em comento, possibilita a compreensão do que se quer pesquisar, dando subsídios para a construção adequada da análise a ser proposta em texto.

Realizado o levantamento de literatura, procedeu-se com as considerações de inclusão dos referenciais necessários para a escrita do texto, onde buscou-se elementos que abordassem a temática discutida, obtendo-se as fundamentações teóricas para tanto. 


\section{Resultados e Discussão}

\subsection{O que é empreendedorismo? Da concepção á definição}

Em termos gerais, empreendedorismo é considerado o envolvimento de pessoas e métodos que, de forma unificada, transformam ideias em ações e consequentemente em negócios de sucesso. De acordo com Dolabela (1999), o empreendedorismo é um neologismo derivado da livre tradução da palavra entrepreneurship e utilizado para designar os estudos relativos ao empreendedor, seu perfil, suas origens, seu sistema de atividades, seu universo de atuação.

Na concepção de Dornelas (2008, p.1) "Empreendedorismo é o envolvimento de pessoas e processos que, em conjunto levam à transformação de ideias em oportunidades". Passos e Martins (2017) descrevem que a nomenclatura empreendedorismo teve início no século XVII, porém foi estabilizado no início do século XIX, no aspecto brasileiro o termo adquiriu maior abarcamento nos anos de 1990.

Para Dornelas (2005) a decisão de empreender pode surgir por dois processos motivadores: Necessidade ou Oportunidade. A disposição baseada na necessidade é aquela em que o novo empreendedor busca uma nova fonte de manutenção da sua existência, e em muitas vezes se aventurando em algo incógnito, com pouco ou nenhum conhecimento do ramo, e em muitas sem planejamento e com pouco investimento. Já o empreendedor por oportunidade é aquele que se vale da ocasião econômica, buscando um nicho de mercado com algum produto ou serviço que pode ser praticado.

O Brasil por suas sucessivas crises econômicas e políticas, gera constantemente momentos tortuosos para os cidadãos e isso faz com que eles se apoiem no empreendedorismo como forma de superar as dificuldades e continuar existindo nos dias atuais e a atuação inovadora de uma startup amplifica o espírito empreendedor.

\subsection{O que é uma startup?}

A definição de Startup, segundo Bicudo (2021) surge da bolha especulativa da internet no início dos anos 2000, caracterizando um grupo de pessoas trabalhando por diferentes pensamentos, firmando ganhos em dinheiro, com um modelo de negócio baseado na repetição e escalabilidade diante de um cenário incerto que é o empreendedorismo. No Brasil, as startups começam a entrar em evidência principalmente no início da década de 2010 onde várias empresas de tecnologia, formada por jovens empreendedores começam a despontar no mercado, investindo quase 13 bilhões de reais (Terra, 2020), na legislação brasileira a lei complementar 167/2019 define startup em seu art. 65-A no parágrafo $1^{\circ}$ como uma empresa de caráter inovador que visa aperfeiçoar sistemas, métodos ou modelos de negócios, de produção, de serviços ou produtos, os quais, quando já existentes, caracterizam startups de natureza incremental, ou, quando relacionados à criação de algo totalmente novo, caracterizam startups de natureza disruptiva.

Segundo Ramos (2020), as Startups através da LC 167/2019 não precisam passar pelo procedimento padrão de abertura de empresas, como registrar os atos constitutivos em junta comercial, por exemplo. Para a criação da startup bastam o preenchimento das informações básicas relativas a empresa, como consta no parágrafo $4^{\circ}$ do art. 65-A:

I - qualificação civil, domicílio e CPF; II - descrição do escopo da intenção empresarial inovadora e definição da razão social, que deverá conter obrigatoriamente a expressão "Inova Simples (I.S.)"; III - autodeclaração, sob as penas da lei, de que o funcionamento da empresa submetida ao regime do Inova Simples não produzirá poluição, barulho e aglomeração de tráfego de veículos, para fins de caracterizar baixo grau de risco, nos termos do $\S 4^{\circ}$ do art. $6^{\circ}$ desta Lei Complementar; IV - definição do local da sede, que poderá ser comercial, residencial ou de uso misto, sempre que não proibido pela legislação municipal ou distrital, admitindo-se a possibilidade de sua instalação em locais onde funcionam parques tecnológicos, instituições de ensino, empresas juniores, incubadoras, aceleradoras e espaços compartilhados de trabalho na forma de coworking; V - em caráter facultativo, a existência de apoio ou validação de instituto técnico, científico ou acadêmico, público ou privado, bem como de incubadoras, aceleradoras e instituições de ensino, nos parques tecnológicos e afins. (Lei Complementar n. 167, 2019) 
As Startups podem se subdividir em diversos tipos, modificando a sua forma de acordo com o negócio em que atua, ainda segundo Bicudo (2020). A primeira é chamada de B2B ou Business to Business, de acordo com a nomenclatura essa startup tem por objetivo principal auxiliar outras empresas, como por exemplo o EBANX que é focada em processos de pagamentos para negócios internacionais (ver Muller, 2020).

Um outro modelo de startup é chamado de B2C ou Business to Consumer, onde o negócio é voltado entre a empresa e o consumidor final, tendo como exemplo a Uber que presta serviço de transporte voltado para o público em geral; ainda existindo um terceiro modelo que é chamado de B2B2C (Business to Business to Consumer) onde uma empresa presta serviço para outra empresa que tem como objetivo final atender a um consumidor na ponta da linha de negócio (Bicudo, 2020), o exemplo mais claro de B2B2C é o ifood, que presta o serviço de entrega de comidas para uma empresa, visando a chegada dela até o cliente final.

\subsection{O que é uma sociedade limitada unipessoal?}

A Sociedade limitada unipessoal está prevista no art. 1052 do Código Civil brasileiro em seu parágrafo primeiro e segundo, surgindo da lei 13.874/2019, que visava desburocratizar a viabilização de criação de empresas no Brasil como mostra o parágrafo primeiro do art. 1052 do CC: $\S 1^{\circ}$ A sociedade limitada pode ser constituída por 1 (uma) ou mais pessoas, "permitindo que a sociedade Ltda. seja constituída por apenas um sócio, permanecendo dessa forma durante toda sua existência. Portanto, todos artigos da sociedade limitada serão aplicados levando em conta essa peculiaridade" (Vido, 2020, p.1).

O parágrafo segundo trata do ato constitutivo da empresa, que foi explicado no tópico anterior, mas complementando o pensamento a doutrina aduz que "como na sociedade limitada unipessoal não há sócios, tampouco há falar em contrato social, mas sim em mero "documento de constituição do sócio único", que deverá observar, no que couber, as normas referentes ao contrato social (art. 1.052, § $2^{\circ}$, do CC).” (Carvalho, 2021, p.1)

Uma das diferenças primordiais da Sociedade Limitada Unipessoal diz respeito, segundo Torres (2021) a não obrigatoriedade na exigência de valores em capital social, possibilitando a empresa a começar suas atividades com um baixo investimento, diferentemente de outros tipos de sociedade limitada, como a Empresa individual de responsabilidade limitada EIRELI em que é necessário um capital social de valor igual ou maior a cem vezes o salário-mínimo vigente.

\subsection{Dificuldades de uma startup}

De acordo com o foi exposto nos parágrafos acima, a startup é um espaço e elemento de negócio inovador ou até, assim considerado, diferente do convencional e toda novidade causa um pouco de receio e de medo de inovar.

A burocracia estatal e o tempo de abertura ou regularização da empresa estão entre as maiores dificuldades que o empreendedor encontra para a legalização da sua ideia empresarial. Todo empreendimento e toda inovação começam inicialmente por uma ideia e em muitos casos, a ideia sai do papel e passa para o plano de execução sem existir a regularidade empresarial, o que torna a execução dessa ideia passível de grandes problemas.

A lei $\mathrm{n}^{\circ} 13.874$, de 20 de setembro de 2019 , comumente chamada de lei da desburocratização, trouxe avanços significativos no que tange a burocracia e diminuição de prazos, trazendo integração de órgãos diferentes, possibilitando que todos os atos se deem de maneira online. Com prazo médio de 3 dias é possível a obtenção do CNPJ da empresa e os demais registro em prazo médio de 30 dias. Ciente desse prazo e antes mesmo até do protocolo de requerimento de abertura de empresa o empresário deve decidir qual será o tipo empresarial ou societário.

Outro fato importantíssimo na constituição da startup é a escolha do regime de tributação apropriado. A maioria dos regimes aplica as alíquotas referentes ao faturamento. Atualmente no Brasil, existem os regimes tributários do simples 
nacional, lucro presumido e lucro real.

Para o empreendedor de startup é essencial identificar qual seria o regime mais adequado, levando em conta o tamanho da empresa, o faturamento e as atividades realizadas. Outro fato que se deve levar em conta, de forma mais apurada inicialmente, é a existência ou não de faturamento inicial, em razão da startup estar nas fases iniciais e sem lucro ou por estar em momento de reinvestimento dos mesmo e assim estar pagando tributos sem necessidade.

Quanto mais inicialmente ocorrer o planejamento tributário do empreendimento, com a escolha do regime tributário e o seu planejamento, mais se evita problemas com a fiscalização ou sonegação por desconhecimento, extinguindo custos e outros acontecimentos prejudiciais.

Em novembro de 2018, o Banco Central do Brasil por meio da Resolução n ${ }^{\circ} 4.697$, de 27 de novembro de 2018, permitiu a abertura de contas digitais para Pessoas Jurídicas de qualquer porte. Depois da resolução citada, vieram outras que facilitaram ainda mais a bancarização das startups, a exemplo das resoluções 4.656 e 4.657 de 2018 e a 4.753, de 26 de setembro de 2019, todas do Banco Central do Brasil.

Entretanto existe uma grande diferença entre criar uma conta bancária e conseguir crédito para iniciar um empreendimento, haja vista as instituições exigirem, em determinados casos, garantias de pagamento. $\mathrm{O}$ fornecimento de crédito pelas instituições bancarias baseiam-se, majoritariamente, em espelho as empresas tradicionais, que quase sempre possuem bens físicos a exemplo de área da sede, estoque, maquinários e outros itens. Entretanto, startups iniciam a maioria dos projetos de forma totalmente digital e as instituições bancárias ainda mantem formas arcaicas de mensurar a escalabilidade do projeto.

Em termos gerais, a concessão de crédito baseia-se na receita bruta ou faturamento dos últimos 12 meses, também chamado de ano fiscal, ou então na previsão de faturamento o que possui uma grande complexidade, haja vista ser dificultoso analisar a escalabilidade e projeção do projeto.

Por mais inovador que seja a atividade que está sendo exercida pela startup e todo o despojamento que exista para a rotina diária de funcionamento, o mesmo não pode ocorrer com a sua organização corporativa. Para os entes fazendários, importa apenas o cumprimento das obrigações nas datas designadas, o mesmo ocorre com o pagamento de salários e de fornecedores.

A existência de uma escrituração contábil clássica, no que tange a pagar impostos, gerenciar os valores financeiros que entram e saem, as contratações e demissões é algo primordial, não podendo ser sonegado ou subjugado, sob de prejuízos e multas posteriores.

A mesma necessidade clássica e pragmática ocorre em relação à cultura organizacional do negócio, pois é necessário determinar todos os valores e a visão que deverá ser seguida na startup. Assim, necessário que o empreendedor, especialmente na gestão de pessoas, determine os planos de carreira, cargos, salários e obrigações contratuais.

A falta de sócios qualificados é um dos maiores fatores que levam as startups ao declínio. Para existir uma sociedade válida é necessário que haja, além dos interesses pessoais, uma junção de sinergias dos sócios. Entretanto pode ocorrer que um sócio "vista a camisa" do empreendimento e o outro fique apenas na espera dos frutos.

Por mais complexo que seja realizar um empreendimento sozinho, as vezes é mais válido agir dessa maneira e evitar mais prejuízos com um sócio que não esteja $100 \%$ dedicado.

Como citado, a Sociedade Limitada Unipessoal é um tipo societário onde não é necessário a existência de sócio para que exista uma limitação da responsabilidade do empresário.

Antes do surgimento desse tipo empresarial, caso o empreendedor que desejasse formalizar o seu negócio de forma individual, ou seja, sem sócios, deveria escolher o MEI - Microempreendedor individual, empresário individual ou EIRELIEmpresário individual de responsabilidade limitada. 
O MEI - Microempreendedor individual, criado pela LEI complementar 128/2008, possui determinações especificas para a atuação, bem como limitação de funcionários e de faturamento, esse último sendo de no máximo de $\mathrm{R} \$ 81.000,00$ (oitenta e um mil reais), ou seja, a criação da startup por esse modo já estaria com limitação de crescimento e de contratação de funcionários.

O outro tipo que possibilita a criação de uma startup de forma solitária é o tipo de empresário individual. Nesse tipo empresarial não existe limitação de atividades e também não existe limite numeral para a contratação de funcionários. Entretanto, nos tipos empresários acima citados não existe separação do patrimônio da empresa e do patrimônio pessoal do empresário. O que também não é possível nos tipos acima mencionados é a transferência para outro titular, e assim, o empreendimento fica impossibilitado de ser adquirido por outro empresário.

O tipo empresarial que possibilita o empreendedor a limitação da responsabilidade vem a ser a EIRELI - Empresa individual de responsabilidade limitada. Entretanto as dificuldades estão relacionadas ao capital que deve ser integralizado para a constituição desta, que vem a ser de 100 salários-mínimos. Esse valor elevado, em 2021 chega ao valor mínimo de R\$ 110.000,00 (cento e dez mil reais) para a constituição, inviabiliza, em muitos casos, a continuidade da startup, haja vista a mesma estar ainda em fase inicial.

O surgimento da SLU veio trazer ao empreendedor a possiblidade de criar um tipo empresarial que não tenha onerosidade excessiva na constituição do capital social, que não precisa de um sócio para ser aberta e que separa o patrimônio pessoal do empreendedor do patrimônio da empresa. Também inexiste limite de faturamento, fazendo com que a startup possa crescer sem gerar problemas fiscais futuros e contratar os funcionários que necessitar.

\section{Considerações Finais}

De forma geral, neste artigo, pretendeu-se analisar o novo tipo societário, o qual vem desburocratizar questões iniciais da constituição de uma empresa como idas a junta comercial para registro, liberação de alvarás e outros.

A quantidade de empreendedores no Brasil faz urgir a necessidade da facilidade de desburocratização na hora de criar uma empresa. Uma vez que, quanto mais facilitado for, maior será a regularização de pequenos negócios e consequentemente do fomento à economia. Assim, legalizar o negócio é imprescindível para o crescimento da empresa, obtenção de recursos, e consequente destaque na ala comercial.

Importante salientar que não é exigível da Sociedade Unipessoal valores robustos em capital social. Nesse sentido, pode-se começar uma empresa com baixo custo. É razoável essa observação, uma vez que nem sempre o empreendedor dispõe de recursos suficientes para todas as necessidades primárias ao abrir o investimento. Assim, o fato de a lei ter oportunizado essa facilidade, contribui diretamente para o aquecimento da economia, bem como do mercado comercial.

De outra maneira, a não obrigatoriedade da existência de sócio, bem como a separação do patrimônio da empresa, do patrimônio pessoal do empresário, são importantes elementos na hora de decidir pela SLU, uma vez que tais fatores fazem grande diferença para o negócio inicial do empreendedor, trazendo mais segurança.

Através do estudo realizado percebeu-se que a Lei n. 13.874/2019 tem caminhado junto ao desenvolvimento da sociedade, onde cada vez mais são necessários avanços mais rápidos e eficazes no âmbito comercial, buscando simplificar a atividade empreendedora, oportunizando desburocratização e facilidades para o brasileiro que deseja abrir seu próprio negócio.

Por ser uma inovação jurídica tem-se ainda pouca discussão doutrinaria e pouca aplicação pratica, mas espera-se que nos próximos anos a sociedade limitada unipessoal atinja um nível de criação que ultrapasse a empresa individual de responsabilidade limitada. 


\section{Referências}

Bicudo, L. (2021, 29 de janeiro). O que é uma startup? https://app.startse.com/artigos/o-que-e-uma-startup.

Brasil. (2002). Lei n. 10.406, de 10 de janeiro de 2002. Institui o Código Civil. http://www.planalto.gov.br/ccivil_03/leis/2002/L10406compilada.htm.

Brasil. (2008). Lei Complementar n. 128, de 19 de dezembro de 2008. Altera a Lei Complementar no 123, de 14 de dezembro de 2006, altera as Leis nos 8.212, de 24 de julho de 1991, 8.213, de 24 de julho de 1991, 10.406, de 10 de janeiro de 2002 - Código Civil, 8.029 , de 12 de abril de 1990, e dá outras providências. http://www.planalto.gov.br/ccivil_03/leis/lcp/lcp128.htm

Brasil. (2018). Resolução n. 4.656, de 26 de abril de 2018. Dispõe sobre a sociedade de crédito direto e a sociedade de empréstimo entre pessoas, disciplina a realização de operações de empréstimo e de financiamento entre pessoas por meio de plataforma eletrônica e estabelece os requisitos e os procedimentos para autorização para funcionamento, transferência de controle societário, reorganização societária e cancelamento da autorização dessas instituições. https://www.in.gov.br/materia/-/asset_publisher/Kujrw0TZC2Mb/content/id/12378952/do12018-04-30-resolucao-n-4-656-de-26-de-abril-de-2018-12378948.

Brasil. (2018). Resolução n. 4.657, de 26 de abril de 2018. Altera a Resolução no 4.606, de 19 de outubro de 2017. https://www.bcb.gov.br/pre/normativos/busca/downloadNormativo.asp?arquivo=/Lists/Normativos/Attachments/50580/Res_4657_v1_O.pdf

Brasil. (2018). Resolução n. 4.697, de 27 de novembro de 2018. Altera a Resolução n. 4.480, de 25 de abril de 2016, que dispõe sobre a abertura e o encerramento de contas de depósitos por meio eletrônico https://www.bcb.gov.br/pre/normativos/busca/downloadNormativo.asp?arquivo=/Lists/Normativos/Attachments/50688/Res_4697_v1_O.pdf

Brasil. (2018). Resolução n. 4.753, de 26 de setembro de 2019. Dispõe sobre a abertura, a manutenção e o encerramento de conta de depósitos. https://www.in.gov.br/en/web/dou/-/resolucao-n-4.753-de-26-de-setembro-de-2019-218821976.

Brasil. (2019). Lei Complementar n. 167 de 24 de abril de 2019. Dispõe sobre a Empresa Simples de Crédito (ESC) e altera a Lei ${ }^{\circ} 9.613$, de 3 de março de 1998 (Lei de Lavagem de Dinheiro), a Lei n ${ }^{\circ}$ 9.249, de 26 de dezembro de 1995, e a Lei Complementar ${ }^{\circ} 123$, de 14 de dezembro de 2006 (Lei do Simples Nacional), para regulamentar a ESC e instituir o Inova Simples. http://www.planalto.gov.br/ccivil_03/LEIS/LCP/Lcp167.htm

Brasil. (2019). Lei complementar n. 167, de 24 de abril de 2019. Dispõe sobre a Empresa Simples de Crédito (ESC) e altera a Lei ${ }^{\circ} 9.613$, de 3 de março de 1998 (Lei de Lavagem de Dinheiro), a Lei n ${ }^{\circ}$ 9.249, de 26 de dezembro de 1995, e a Lei Complementar $n^{\circ} 123$, de 14 de dezembro de 2006 (Lei do Simples Nacional), para regulamentar a ESC e instituir o Inova Simples. http://www.planalto.gov.br/ccivil_03/leis/lcp/lcp167.htm.

Brasil. (2019). Lei n. 13.874, de 20 de setembro de 2019. Institui a Declaração de Direitos de Liberdade Econômica; estabelece garantias de livre mercado; altera as Leis nos 10.406, de 10 de janeiro de 2002 (Código Civil), 6.404, de 15 de dezembro de 1976, 11.598, de 3 de dezembro de 2007, 12.682, de 9 de julho de 2012, 6.015, de 31 de dezembro de 1973, 10.522, de 19 de julho de 2002, 8.934 , de 18 de novembro 1994, o Decreto-Lei $n^{\circ}$ 9.760, de 5 de setembro de 1946 e a Consolidação das Leis do Trabalho, aprovada pelo Decreto-Lei ${ }^{\circ}$ 5.452, de $1^{\circ}$ de maio de 1943; revoga a Lei Delegada $n^{\circ} 4$, de 26 de setembro de 1962, a Lei $n^{\circ} 11.887$, de 24 de dezembro de 2008 , e dispositivos do Decreto-Lei ${ }^{\circ} 73$, de 21 de novembro de 1966; e dá outras providências. http://www.planalto.gov.br/ccivil_03/_ato20192022/2019/lei/L13874.htm

De Carvalho, D. (2021). Direito Empresarial. Cp Iuris.

Dolabela, F. (1999). Oficina do Empreendedor. São Paulo: Ed. de Cultura.

Dornelas, J. (2008) Empreendedorismo: transformando ideias em negócios: Elservier.

Dornelas, J. Empreendedorismo Corporativo: Como ser empreendedor, inovar e se diferenciar em organizações estabelecidas. Rio de Janeiro: Elsevier, 2008.

Gil, A. (2008). Métodos e Técnicas de Pesquisa Social. São Paulo: Atlas.

Lakatos, E., \& Marconi, M. (2007). Fundamentos da Metodologia Científica. São Paulo: Atlas.

Massensini, A. (2011). Empreendedorismo. Curso Técnico de Administração. Brasil: Ministério da Educação. http://www2.pelotas.ifsul.edu.br/ faili/lib/exe/fetch.php?media=empreendedorismo_completo_02_1_.pdf

Muller, J. (2020, 21 de dezembro). O que é B2B: principais características, prós e contras. https://leads2b.com/blog/o-que-e-b2b/

Terra Networks Brasil S. A. (2020, 18 de fevereiro). Crescimento de startups no Brasil é impulsionado por empreendedores. https://www.terra.com.br/noticias/dino/crescimento-de-startups-no-brasil-e-impulsionado-por-

empreendedores,9a8232f0a6f6aed72f8bc967659844e00b5y1lqe.html

Vido, E. (2020). Curso de direito empresarial. São Paulo: Saraiva. 